\title{
O papel estratégico da cultura organizacional na construção da personalidade no trabalho
}

\section{Resumo}

A estratégia e a cultura organizacional utilizam-se das normas organizacionais para construir um novo sujeito - a personalidade daquele que trabalha. A partir desta reflexão pode-se pensar que o trabalho é uma mídia e a empresa é um espaço que constrói e desconstrói personas profissionais.

A investigação pressupõe a compreensão entre a comunicação, cultura e missão organizacional. Esses fatores dependem do sujeito interpretante que se dirige à esse espaço, para alimentar seus vínculos. A sua comunicação com a empresa se faz por meio da missão, e o trabalho torna-se a interface, a representação do real. A missão funciona como mentora da mídia "trabalho", o seu discurso atrai o nômade, seda-o, afastando-o do senso e aproximando-o da loucura. Mantém-no refém, doa-lhe competência e sanciona-o positiva ou negativamente. Esse sistema de comunicação conduz a existência do sujeito, em estado alterado de consciência, e o seu corpo dá lugar à identidade coletiva, ele coloca o seu poder no fazer da empresa, espaço de construção e desconstrução.

Palavras-chave: Comunicação e Cultura Organizacional; Comunicação Estratégica; Sistemas de Comunicação; Universo Simbólico; Vínculos Comunicacionais.

\section{Abstract}

The strategy and organizational culture make use of organizational standards to build a new individual - the personality of him who works. From this reflection one might think that work is a medium and the company is a space that constructs and deconstructs professional personas.

The research assumes an understanding of the connection between communication, culture and organizational mission. These factors depend on the interpreting subject who comes to this space to strengthen his ties. His

\footnotetext{
${ }^{1}$ Claudinei Senger - Mestre em Direito Internacional pela UNISANTOS/SP . Prof. das Faculdades integradas "Campos Salles" - FICS-SP. Prof. Pesquisador do Grupo de Pesquisa da Faculdade ENIAC desde 2009. Compõe desde o início de 2012 o grupo de pesquisa, orienta Iniciação Científica é co-editor da Revista Acadêmica Augusto Guzzo. www.campossalles.edu.br /ISSN 1518-9597.

2 Mauricio Pedro da Silva - Graduado em Administração pela UNG. Especialista em Educação e Docência. Prof. pesquisador do grupo de pesquisa da Faculdade ENIAC desde 2009. Compõe desde o início de 2012 a Comissão de Edição, Revisão, diagramação e Editoração Eletrônica da Revista Revista Acadêmica Augusto Guzzo. www.campossalles.edu.br /ISSN 1518-9597.

${ }^{3}$ Mônica Maria Martins de Souza - Doutora em Comunicação e Semiótica pela PUC/SP. Mestre em Administração de Empresas pelo Mackenzie SP. Especialista em Administração de RH. Especialista em Tecnologia Educacional. Psicóloga e jornalista. Atual Profa convidada Pós-graduação do Mackenzie. Desde 2006 é avaliadora INEP. Profa. Pesquisadora da Faculdade ENIAC, coordena grupo de Pesquisa e Iniciação Científica, organiza Seminários Anuais desde 2009 e da Revista Acadêmica ENIAC PESQUISA. É Profa. Pesquisadora, coordena Cursos e a Revista Acadêmica Augusto Guzzo nas Faculdades Integradas Campos Salles - FICS - SP, desde agosto de 2010. Consultora da Euroatlantica Ghesa Brasil Ltda.
} 
communication with the company is made possible through the mission, and work becomes the interface, the representation of reality. The mission operates as the media mentor "work", its discourse luring the nomad, sedating him, drawing him away from his senses and bringing him closer to madness. Keeping him hostage, it gives him powers and sanctions it positively or negatively. This communication system leads to the existence of the individual in an altered state of consciousness, his body giving way to the collective identity; he devotes his efforts to the way of doing things of the company, a space of construction and deconstruction.

Keywords: Communication and Organizational Culture, Strategic Communications, Communications Systems, Symbolic Universe; Communicative Links

\section{Introdução}

Para compreendermos o sentido do trabalho como mídia no contexto da cultura organizacional pelo viés da semiótica, buscamos em outras áreas, elementos e conceitos que compõem a rede interdisciplinar ${ }^{4}$. Consideramos que cultura é um sistema de símbolos e significados compartilhados, que necessitam ser interpretados, e decifrados para serem entendidos, pois é a mente humana que gera a cultura. Sendo o trabalho um instrumento a serviço das necessidades biológicas e psicológicas do homem, ele funciona como um mecanismo adaptativo-regulador e unifica os indivíduos nas estruturas sociais, no caso desta pesquisa as organizações. Lembramos que organizações são organismos adaptativos existentes nos processos de troca com o ambiente. Sistema de conhecimento que repousa na rede de significados dos membros que compartilham esse espaço.

Nesta contextualização o trabalho transforma-se em signo midiático e adquire novo sentido e nova interpretação. Ele existe para satisfazer o caráter insaciável do homem na empresa, que o socializa e o capacita a criar uma rede de signos sob seu domínio, que as vezes o domina 5 . O homem e a empresa são mutuamente dependentes desses signos, e uma complexa rede destes, constituem o seu universo ${ }^{6}$. Neste espaço de limitações e possibilidades o homem desenvolve relações que promovem o seu reconhecimento ou provoca a sua sanção. A sua interpretação do trabalho é dependente da sua ideologia, sua crença e dos fatores que o constitui. A forma como vai designa-lo depende do seu condicionamento social e sua rede significante, positiva ou negativa. Entender sua relação nesse espaço requer também compreender a filosofia e a política organizacional, com a sua estrutura simbólica de poder, e sua pratica comunicativa. A cultura da empresa se reflete em sua missão, seus objetivos e suas metas. E a estratégia utilizada para conceituar suas relações singulares com o homem fundamentase em sua história. Talvez esse seja o suporte para compreender as construções e desconstruções humanas, reais e metafóricas das quais trataremos a seguir.

\section{O tempo, o investimento e a mudança: uma fratura ambivalente}

Como trabalhar hoje, não é mais produzir apenas, mas, entrar no sistema de ordem que é a empresa, neste contexto vamos vislumbrar o

\footnotetext{
porquanto só é definível o que não tem história.

${ }^{5}$ Norval baitello. O animal que parou os relógios, 1997.

${ }^{6}$ Harry Pross, Estructura Simbolica del poder, 1980:36.
}

4 Segundo Nietzche - Todos os conceitos em que um processo se resume semioticamente escapam à definição, 
trabalho como meio, veículo e canal de comunicação entre o homem e a empresa. Vislumbrar sim, e não iluminar, porque todo objeto sobre o qual se deita o holofote, ofuscase. E nosso objetivo é aproximar-nos da compreensão desse trabalho que media o homem "sujeito" com o seu objeto valor, a "empresa". É o trabalho que anuncia e denuncia esse sujeito para o objeto, através do seu fazer, tendo como diretriz uma ferramenta enigmática, persuasiva, sedutora e provocativa que é a missão da empresa. Nessa relação, o trabalho que propicia o estar conjunto no sistema, é a ferramenta que também, dirigida pela missão, conduzirá o homem por labirintos, onde ele se desnudará de sua identidade individual e se vestirá com outra roupagem, a sua nova identidade, a identidade coletiva. A missão enquanto mentora dessa mídia "trabalho" doará ao sujeito a competência adequada para que ele seja sancionado positivamente pela empresa. Sendo o homem um ser que vive de rituais, a sua comunicação é uma representação. E neste caso, o trabalho a representação que funciona como signo midiático com a função de promover a conjunção do homem com a empresa.

O próprio "nome" do homem não é o homem, é o que o representa, existe por ele 7 . E a missão é o instrumento utilizado para a manipulação da sua mente, operação realizada através das estratégias da comunicação. A comunicação dirigida dessa mensagem incita o contrato fiduciário que se consolida nesse tempo/espaço (Oliveira, 2002, 149).

\section{A costura que não se desfaz}

Homem e empresa são enredados pelo lastro do vínculo comunicativo, através da comunicação que media a relação entre os actantes, sujeito e objeto, instalados na relação de doação e aquisição de competência. O sujeito para adquirir pertença adota os valores do objeto valor e com ele se compromete. Consideramos aqui, que objeto, é aquele que mantém laços com o sujeito e a relação entre ambos é o que lhe proporciona a existência. A sua existência, enquanto ponte entre sujeito e objeto cria a natureza midiática. E são as normas da missão que deflagram as atitudes desejáveis que sutis a princípio que evoluem para um exagero de fidelidade, e trabalho em primeiro lugar, que faz do tempo do homem o tempo da empresa e isso gradativamente devora a sua existência enquanto indivíduo (Barros, 2001:17).

Sabendo da sua dependencia do sistema de ordem para alimentar seus vínculos a empresa cria uma rotina que consome o homem e o seu tempo. Sistema esse que é estabelecido a priori, e do qual, o homem responde segundo as suas expectativas. Neste espaço o sujeito atua, "veste a camisa", adota comportamentos dirigidos, e a partir disso, delimita o seu cotidiano. O seu fazer e o seu lazer é programado pela empresa. Inserido e comprometido nesse contexto, acredita que pode realizar o propósito de ambos ${ }^{8}$. Iludido nesse jogo de faz de conta, aliena-se de seus objetivos pessoais e abraça os da empresa buscando a sua realização como se fossem os seus proprios (Huizinga, 1996). E, a identidade que precisa ser protegida para garantir a sanidade do ser, nesse processo é esvaziada de si mesma. Essa identidade extraviada provoca

\footnotetext{
${ }^{7}$ Harry Pross, Estructura Simbolica del poder, 1980.

${ }^{8}$ De acordo com Morin, essa convivência, só é possível em virtude da submissão dos indivíduos. 
um movimento de afastamento do senso e a aproximação da loucura segundo Kamper ${ }^{9}$. Esse fenômeno envolve uma mudança na percepção da existência, pois, o homem deixa de ver a realidade com a sua visão de mundo, que é a soma dos seus conceitos e preconceitos culturais. Ou seja, deixa de ver com os olhos ingênuos do nômade montanhês de Flusser $(1979)^{10}$, isso é o que ocorre com o indivíduo que entra na empresa. Uma vez, nela inserido, ele adquire novos mapas mentais através das normas organizacionais.

Essas normas nada mais são do que discursos simbólicos da missão, estrategicamente articulados que ditam os valores que governam o coletivo. E nele não há norma, axiologia, ou ética, desvinculada da organização. A missão da empresa constrói uma identidade como a escola, a família e a sociedade, com visão e crenças compartilhadas em sua micro-estrutura ${ }^{11}$, a sua filosofia e sua política posicionam-se a partir da sua visão. Neste espaço ocorrem sucessivas palestras e treinamentos com o intuito de operar mudanças que gerem transformações no estado do sujeito, como a aquisição da competência que o qualifique ao poder, saber, fazer da empresa. A sanção positiva do sujeito pela empresa significa a sua aceitação, porém ai deflagra uma fratura, pois a sua entrada neste "universo mágico" implica na perda da liberdade e dos valores individuais, ou seja, a disjunção com a própria identidade. A busca da conjunção com a empresa, custa ao sujeito a penitência de uma nova performance. Ele abre mão da primeira realidade $^{12}$ e incorpora o novo modelo coletivo para ajustar-se perfeitamente ao molde oferecido. A sua construção neste sistema, desconstrói o seu conjunto de hábitos e convenções anteriormente reguladoras do seu viver. No contexto organizacional o que governa o homem, é o conjunto de ações coletivas e as práticas sociais com as quais todos dialogam. Essas práticas promovem um conhecimento com o qual todos eleitos devem se identificar. Neste espaço não se permite desviar a energia da libido para outros objetos que não seja a empresa (Barros 2001:14). Podemos entender aí o conceito saussureano da relação entre língua e fala, história, passado, diacronia e sincronia, presente entre texto e contexto. $\mathrm{Na}$ empresa não há a concepção de língua isolada e individual, apenas a coletiva, resultado de acordos sociais.

Consideramos que o que move as pessoas em uma comunidade são suas crenças, valores, superstições, e os emblemas criados. No caso da empresa o que governa as pessoas nesse espaço é a logomarca, que sintetiza a sua missão. O signo emblemático da logomarca traduz a idéia de coletividade da empresa. Os fatos da sua cultura e a sua relação com as metáforas que emergem desses signos podem ser observados na missão da empresa. Essas formas organizacionais são formas estéticas com arranjos de maior ou menor teor de

\footnotetext{
${ }^{9}$ No texto de Kamper sobre a loucura ele ressalta que: o que diferencia da loucura é o senso.

10 No livro Natural:mente, Flusser fala que o homem é nômade, nasce nos vales e vai até os cumes para adquirir informações e construir outros mapas mentais e vive-versa. 11 Segundo Morin “A sociedade é o conjunto de homens com grupos de diversas dimensões e significados que
compõem a humanidade".

12 O conceito de "Primeira realidade" de Bystrina, envolve a sobrevivência e a realidade das necessidades. O universo da civilização, a educação do corpo e dos hábitos para a sociabilidade. Para a comunicação a "Primeira realidade" é o lugar onde espaço e tempo intercruzam com a mitologia. Portanto, a "Primeira realidade" e "Segunda realidade", se contaminam reciprocamente para dar origem ao abstrato conceito de tempo/ espaço.
} 
esteticidade, articulação, organização e construção do enredo, um todo articulado de sentido proposto pelo enunciador. Metáfora de um enredo que em ação contínua, consciente ou não os seus atores tecem, ignorando que é escassa a possibilidade de desenredar. O enredo da missão da empresa é seu constructo, sua identidade, não importa o seu nome, mas o seu papel social. Na conjunção com o outro a empresa busca a sua existência de fato, a sua visibilidade, e a realização do seu fazer através do outro, pois, sem este que a constitua e lhe de vida ela não existe ${ }^{13}$. Por isso numa ação continua, ela acena para os homens com papéis fixos; consagrados como os dos deuses, míticos como os das lendas e funcionais como os da sociedade (Serres 2001). Acena atraindo o sujeito a sedar-se. E seduzido pela mensagem, ele atende ao chamado, buscando através dela a competência de um Deus para se tornar um sujeito de fato e de direito. Ele esquece ou ignora que os deuses são segunda realidade, portanto imagem. Desta forma o que ele busca é o modelo da completude da imaginaria "normalidade"14, prometida pelas mensagens elaboradas a partir do repertório da empresa que compõem a missão, metáforas que o induz a estruturar intenções, comportamentos e a formar a consciência coletiva (Iasbeck, 2002). Ignorando que este é o espaço que promove a sua construção ou desconstrução.

A leitura das ferramentas semióticas eficientemente persuasivas nos permite analisar no sujeito a incorporação de práticas culturais exteriorizadas nas suas interações cotidianas. Assumindo esse repertório, o individuo identifica-se a tal ponto com os seus objetivos e metas que tende a anular a sua individualidade e criar uma comunicação especifica mediada pelo trabalho. Podemos observar que essa comunicação é visual e cognitiva, ela denuncia uma ordem sensorial da apreensão inteligível, e aqui toda a atitude do sujeito é governada pela missão da empresa, enquanto conhecimento, forma e sentido ${ }^{15}$. Na sua vontade de conjunção ele incorpora a performance, o ideal de competência idealizado pela empresa. Inserido no mundo dessa cultura adota os seus valores e demonstra novas atitudes ${ }^{16}$. Nessa relação ele encena e se faz contemplar enquanto simulacro em um mundo simbólico onde os signos falam das relações sociais ${ }^{17}$. Na busca pela analise desse simulacro buscamos em um site de domínio público a missão de uma empresa de alimentos e destacamos alguns fragmentos e seus desdobramentos.

\section{Da primeira realidade à superfície da imagem: uma trajetória sem retorno}

Podemos observar que na narrativa da missão, visão, objetivo, abordagem e medidas de desempenho, a empresa busca a conjunção com os atores do seu contexto. Confirmando os tópicos até apresentados.

Um dos fragmentos do texto diz:

A empresa iniciou o século 21 com um novo desafio: "tornar-se na próxima década, a principal provedora de soluções para nossos clientes dos setores agrícolas e de alimentos". Reconhecemos que somente obteríamos sucesso em nosso negócio se

\footnotetext{
13 Para Morin, todo indivíduo tem importância na empresa para a qual colabora com sua própria complexidade, sua visão do mundo, seus projetos pessoais, suas atitudes imprevisíveis, suas estratégias, sua dinâmica de evolução. Para ele a empresa é "a sua" representação da empresa.

${ }^{14}$ Morin considera que o mito do modelo ideal é um fantasma comum que leva empresas e funcionários a fracassarem.

15 Floch, 2001.

${ }^{16}$ De acordo com Morin, presos em seu trabalho e em sua visão particular das coisas, as pessoas arriscam-se a não mais considerar senão o ponto de vista da empresa, e se fecham em um reducionismo estreito.
}

${ }^{17}$ Pressuposto sociológico de Cassirrer. 
criássemos valores diferenciados para nossos clientes. Levamos para esta jornada; nossos tradicionais pontos fortes que são integridade e confiabilidade. Também trazemos nosso conhecimento e experiência, acumulados pela nossa atuação nas mais diversas localidades, produtos e serviços. A partir desta base, formaremos relacionamentos mais sólidos com cada cliente, possibilitando:

Explorar necessidades não atendidas;

Descobrir juntos as melhores maneiras de atendê-las;

Criar soluções únicas e valorizadas; e

Entregá-las de maneira confiável.

Adotamos, como empresa, esta missão e ela reflete como vemos o futuro.

O nosso novo logotipo e o sistema de identidade corporativa também representam as aspirações da nossa companhia. Estas mudanças são poderosos símbolos de uma empresa mais dinâmica, acessível e inovadora na qual estamos nos tornando.

O estilo da logomarca desta empresa dá a impressão de movimento, ação, interação e dinamismo, é a clara indicação de um simulacro inscrito no espaço, o que equivale ao ausente da imagem. Colocando-se em perspectiva diacrônica, ele se inscreve como agente e testemunha do seu próprio devir, exaltando através da idéia de ação, o investimento no crescimento para aumentar a sua participação no mercado. Seguido do enunciado da missão, reduzido ao estado de mensagem, ele é o equivalente simbólico com pretensão a uma prospecção. Sabemos que o logo não é a empresa, mas está no lugar dela, nos remete a ela, chama através da sua visualidade todo o seu texto e o seu contexto, mas é apenas a inscrição do real.

Com relação à visão da empresa o texto relata:

A visão da empresa expressa as aspirações coletivas das pessoas que aqui trabalham. Ela nos unifica, dirige nossos esforços e nos diferencia das outras empresas. Possui quatro elementos:
Nosso Objetivo: é ser líder mundial em alimentos.

Nossa Missão: é criar valores diferenciados.

Nossa Abordagem: é sermos dignos de confiança, criativos e empreendedores.

Nossas Medidas De Desempenho: são funcionários engajados, clientes satisfeitos, comunidades enriquecidas e crescimento rentável.

O nosso Objetivo: "Alimentar as pessoas" reflete nosso enfoque agrícola e em alimentos, e a idéia mais ampla de melhorar a qualidade de vida das pessoas. Isto também quer dizer que o nosso objetivo fundamental é atrelar nosso conhecimento e energia para oferecer produtos e serviços necessários para a vida, saúde e crescimento. Implica em cumprir um leque de expectativas, desde aprimorar a produtividade agrícola até melhorar os alimentos para promover um desenvolvimento econômico sustentável. Também transmite uma cultura de alimentar com base na confiança, valorização das relações e na realização de todo o seu potencial.

A nossa Missão: "Valor diferenciado" está no centro da Ação Estratégica. Encontra-se nos pilares do foco do cliente, inovação e alto desempenho. Enquanto o nosso objetivo de longo prazo trata da busca por nossas metas, nossa missão reflete a realidade competitiva do mercado. Só obteremos sucesso nos negócios criando valor agregado para nossos clientes, nossos fornecedores, funcionários, acionistas e vizinhos. Criar um valor diferenciado significa construir relações mais fortes com os clientes e apresentar comportamentos orientados para a solução do cliente que podem se resumir na frase: Explorar, Descobrir, Criar e Entregar.

Podemos observar que na seqüência narrativa da visão e da missão elas conferem sentido ao enunciado ${ }^{18}$. O jogo de sedução que aqui se joga, é analisado como processo recursivo, fundado na reprodução especular de posturas, que se espera, sejam adotadas alternadamente por uns e outros. Enunciação e enunciado atualizam a competência, de um ser que representa um papel, que não passa de um simulacro. $\mathrm{O}$ apelo místico da visão exalta o ser humano enquanto animal simbólico que age

${ }^{18}$ Fiorin, 1996, Oliveira 2003. 
dentro de uma ideologia. Se na cultura o mito pode ser definido como a concretização de uma verdade coletiva, aqui se não é a sua concretização, tem a intenção de destruir as dúvidas essenciais, individuais ou coletivas a seu respeito. As pessoas inseridas nesse contexto apresentam atitudes que denunciam desejo de fazer dessa "verdade" uma realidade ${ }^{19}$.

$\mathrm{O}$ enquadramento e a inserção das informações acima, são elementos semióticos capazes de promover ou fazer surgir efeito de sentido. "Alimentar o mundo", pelo procedimento de textualização, o seu discurso verbal procura ser atraente, o conteúdo enuncia e define a disposição dos atores em uma figuratividade sinestésica ${ }^{20}$. Instaura uma gestualidade no corpo desde o início da sua inserção na empresa e vai adquirindo um "ritmo", comportamento, linguagem, postura, forma de expressão verbal e não verbal, deixam de ser mídia primária e transforma-se em inscrição. Ambos, sujeito e objeto buscam a conjunção para encontrar a plenitude que na verdade é do domínio do imaginário, mesmo que a encontrem por um momento, a ela enquanto eterna construção pode se romper. Mas essa informação a missão não explicita, e busca afastar o desconhecido que é figurativizado. Essa mensagem fica oculta, o funcionário mantém-se na relação coletiva com o desconhecido, o mundo do opressor e do oprimido. Embriagado pelo desejo de poder, saber, fazer ele trabalha para afastar a angustia da não pertença ${ }^{21}$. Ávido pela possibilidade de conjunção o sujeito se potencializa, exalta-se em sua fidelidade, lealdade, e dedicação incondicional. O conjunto das mensagens, atinge a sua intenção de comunicação do caráter, imagem e personalidade da empresa no "caminho para privilegiar um sentido desejado e intencional" (Barthes, 1974: 19), persuasiva e carregada de intenções ideológicas ${ }^{22}$.

O repertório emotivo dos signos perfila desde o século XVII, com o desenvolvimento da industrialização. Dessa época a missão se apropria do grau emotivo, com a pretensão de empolgar o destinatário e sensibilizar sua opinião. Utilizam-se de termos e expressões que sugerem sedução, que no texto dessa empresa fica muito evidente; "quer fazer parte da nossa equipe?" "Nós alimentamos o mundo" aqui encontramos apelo significativo de linguagem afetiva. "Quer alimentar o mundo? nós ajudamos você, desde que se integre ao nosso corpo coletivo". A mensagem invoca conceitos culturais muito ligados aos valores explorados na atualidade como a ecologia, a solidariedade, a não violência e a fraternidade, entre outros, como sugere o texto a seguir:

Nossa Abordagem - "Ser digno de confiança"
inspira integridade na relação que
construímos com o cliente. "Ser criativo"
remonta à missão de desenvolver soluções
para o cliente. "Ser empreendedor" tem a
conotação de uma empresa que pensa à
frente e é orientada pela ação. Nossas Medidas de Desempenho; reconhecem que o alto desempenho começa com funcionários engajados que enfocam os esforços na satisfação do cliente, e que testemunham nosso compromisso em comunidades habitáveis e sustentáveis. E

\footnotetext{
19 Morin considera que: administrar diversidade de dinâmicas individuais imbricadas, querer fazer viver e trabalhar juntas para a realização de objetivos comuns, pessoas também singulares e autônomas, é realmente um desafio que causa vertigem, e suscita admiração ao mesmo tempo.
}

${ }^{20}$ Greimas, 1993, Oliveira 2002

21 Morin diz que as pessoas em uma empresa, não vivem fora do tempo, fora de sua história, fora de seu ambiente. Estão inseridas em um contexto cultural, econômico, social do qual dependem e onde se moldam. Esta dependência recíproca introduz um fator suplementar de complexidade na administração. Os seres humanos são fruto de uma linhagem, de um povo, de uma região que forjaram suas tradições e suas crenças.

22 Morin chama atenção para a cultura das empresas que de alguns anos para cá, tem uma tendência a se fechar e a reproduzi-la. 
elas refletem que organizações que apresentam estes comportamentos terão o crescimento lucrativo necessário para sustentar o desempenho do tempo.

\section{Construção imaginária}

Convictos da possibilidade da conjunção, empresa e funcionário, mediados pelo vínculo "trabalho", identificam-se. Nessa relação se estabelece uma tipologia onde o "corpus", trabalho dirigido pelas mensagens da missão atua como vinculação e mediação. A evolução nessa relação atinge tamanha cumplicidade que o papel do trabalho deixa de ser o direcionador do sujeito em direção ao objeto valor, e passa a transitar entre dois sujeitos como elo. Isso permite ver que o papel do trabalho se constitui como continuidade ou, se rompido, descontinuidade. Enquanto continuidade o trabalho enuncia, destaca e fala do sujeito que agora coletivo, coloca o seu poder, no fazer da empresa que define o seu existir. $O$ poder da missão que demarca para o sujeito, a hora de fazer, e indica o que, como, quando e em que direção ele deve caminhar. E se for descontinuidade, a relação se rompe não há o que caminhar.

\section{O nomadismo e sedentarismo: um} divisor de águas

A partir do papel do trabalho, e da construção do vínculo permanentemente alimentado, homem e empresa unificam-se, muito mais do que proximidade física eles passam a viver em intima interação, facilitada pela tecnologia da informação. Hoje, na empresa, os homens não apenas manuseiam uma ferramenta apertando um parafuso, permitido pela liberação da mão com o advento da hominização. Com as mãos livres eles adquirem a competência e, metaforicamente passa a ter o mundo nas mãos. Porém, a manipulação não se limita às mãos, o seu mundo de acesso vai muito além. O ser destinado à liberdade, queda-se aprisionado pelo sedentarismo, "agregado" na empresa e seduzido pelo espaço organizacional. Espaço de comunhão onde coexistem competências, ineficiências e $\operatorname{conflitos}^{23}$. Envolvidos, eles exercitam o poder sobre si mesmos, gregários da própria opressão, contaminados pela loucura da vaidade, do desejo de status, que domina neste cenário $^{24}$, possuídos pela ilusão dos imortais no reino dos mortos, tentas aí fincar seus pés. Condição ilusória e apaixonante desses corpos inventados nesse tempo espaço sujeito à ventura, destino da imagem (Kamper) e razão da loucura, segundo Foucault.

Nos homens encontramos as mais diversas características; oscilando de "stulticiae" loucura, a "Kolaxia" avareza. A personalidade humana é estudada desde os tempos mais remotos, e os seus estereótipos são estrategicamente pesquisados e desenhados para se enquadrarem nos mais diversos estratos das esferas sociais. Os homens possuídos pela ambição são atraídos pelas equipes de seleção que encaixam suas características passíveis de adaptação aos perfis dos cargos das cavernas da modernidade. Ao longo de sua caminhada, alguns são sedados pela cultura organizacional, e nesse espaço se estabelecem, exercem o poder e acumulam bens. Nômades iludidos em domesticar sua personalidade selvagem, caem em armadilha auto-preparada, pois conscientes ou não aceitam esse pacto de sedação, acreditando estar no caminho adequado ao que chamam de evolução e progresso. O sistema de ordem seda aqueles que atendem a sua

\footnotetext{
${ }^{23}$ Segundo Morin, os fenômenos de regulagem dos jogos dos atores nas organizações são extremamente entravados e 'récursivos'. Os conflitos, os incidentes, as desordens diversas que surgem, são fenômenos ligados entre si.

24 Flusser na obra “A História do Diabo". São Paulo: Martins Fontes, 1965. Estabelece cenários com realismo hipotético e bases antropológicas que lhe valem a alcunha de futurólogo da mídia. Ele fala que nesses cenários os homens dançam, com as máscaras e alegorias de deuses e demônios, e aí sedam suas mentes.
} 
necessidade potencializando a sua superfície imagética, construindo seres coletivos que possam permanecer devoráveis o mais longo tempo possível. Aos que não se permitem desconstruir, a empresa descarta sem carpir, como seres humanos excrementais. Como bem define Kamper, o que pode transformar em imagem permanece, o resto naufraga.

Os indivíduos que entram na empresa, prado mágico e mítico da cultura organizacional, entram em contato com outros mapas existenciais e adquirem uma identidade coletiva. Mergulhados no abismo da superfície da imagem, da alienação massificada eles perdem definitivamente o contato com a mídia primária, a primeira realidade de acordo com Bystrina. E, como disse o Flusser; os homens que sobem o caminho, em sentido contrario, ao sentido que corre as águas dos rios, retornando ou não, adquirem e armazenam informações que os condenam a permanecerem contaminados sem jamais voltarem a se integrar. Eles experimentam o limite da loucura do espírito humano ${ }^{25}$, lugar de deciframento e não de respostas.

\section{Considerações Finais}

Considerando a organização como o espaço do trabalho "veículo midiático" dirigido pela comunicação persuasiva da missão, podemos pensar que essa ideologia uma vez absorvida pelos indivíduos, dilacera vorazmente a sua primeira realidade ${ }^{26}$ lançando-a em abismos fantasmagóricos. Atormentados e incapazes de identificarem seus corpos, e suas identidades, e apropriarem-se de seus destroços para tecerem novos vínculos, os homens permanecem tateando a imagem. Perde o contato com o seu ser e o seu corpo cede lugar ao outro. A este processo Bateson chama de esquizofrenia, Foucault e Erasmo de loucura. Dejours chama de doença profissional, que é que o percurso do viajante surpreendido pelas tabuletas invertidas por Hermes, o deus alado da comunicação. Para Bystrina é uma das raízes da cultura; os estados alterados da consciência. Os psiquiatras chamam de alteração ou desvio do comportamento designado como padrão de normalidade. Resta-nos então a pergunta: Qual normalidade?

Nesta investigação observou-se que o trabalho, enquanto veiculo midiático, a comunicação é utilizada, como um artifício que se propõe a desconstruir o individuo, para trabalhar na linearidade engessando-o, privando-o, e enquadrando-o às suas normas e modelos. O pensamento do homem, porém, em sua natureza nômade é livre e vive aos saltos, muitos não se permitem entrar na linha. A identidade corporativa cria sua cultura, e através da missão enlaça e embriaga quem nela se permite refém. Mas, os portadores de uma expressão voraz, inflamados pela imaginação e pela criatividade, surta, fazendo ponte com a vanguarda do exército do espírito humano ${ }^{27}$ que alavancou a natureza, inventando o fogo, através do atrito entre as pedras.

Refletindo sobre as palavras de Morin ${ }^{28}$; o trabalho científico é sempre uma iniciação e jamais uma conclusão. O estudo na verdade é uma provocação e o seu fazer está sempre por começar e jamais concluído definitivamente.

\footnotetext{
${ }^{25}$ Flusser em Natural:mente, 1979, autor tcheco, judeu, brasileiro, que escreveu sobre o estrangeiro e sua incapacidade de se integrar a outros paises por possuir outros mapas mentais compostos pela cultura do seu país de origem.

${ }^{26}$ A primeira realidade é um conceito de Ivan Bystrina que envolve a sobrevivência, a realidade das necessidades, e a "Primeira e a Segunda realidade", se contaminam reciprocamente para dar origem ao abstrato conceito de tempo/ espaço.

\section{Flusser, 1979}

28 “...em tudo que escrevo (...) não há verdades senão parciais, relativas e temporárias. Imersos na complexidade, somos obrigados a distinguir certos aspectos das situações, analisá-las localmente e simplificá-las para poder apreendê-las. Isto é um fato que requer o máximo de descentralização e de delegação de responsabilidades.
} 
Amparando-se em Prigogine, em "O Fim das Certezas", sabe-se que mesmo que um dia se possa fazer uma conclusão ela estará por ser repensada, e contestada, pois, a ciência traz o eterno retorno. É grande a complexidade e a diversidade de idéias dos autores que dialogam sobre os temas da comunicação que indicam o caminho na direção da construção e desconstrução do homem. Esse estado de mudanças do nômade, que se queda sedado na organização colocando o seu pé na loucura ou atolando-se nela tem a natureza do fogo e da pedra, do ar e da água, e esses elementos estarão sempre interagindo e complexificando a sua natureza. Cabe ao pesquisador resistir ao poder da sedução ou vencer a sua astúcia.

\section{Referências bibliográficas}

BAITELLO, Norval. O animal que parou os relógios. 2ª, edição. São Paulo: Annblume,1999.

. A cultura de ouvir. In Bentes, I. Zaremba, L. Rádio Nova. Constelações da radiofonia contemporânea. Rio de Janeiro: Publique, 1999.

BATESON, Gregory. Steeps. To na Ecology of mind. São Francisco, Chandler, 1972.

Metadiálogos. Lisboa: Gradiva, 1989.

BYSTRINA, Ivan. Tópicos de Semiótica da Cultura. São Paulo, PUCSP - Cisc., 1995.

CASSIRER, Ernest. Linguagem e Mito. São Paulo: Perspectiva, 1978.

FERRARA, Lucrecia. Os Significados Urbanos. São Paulo: Edusp/Fapesp, 2000.

FIORIN, J. L. Elementos da análise do discurso. São Paulo: Contexto, 1994.

FLUSSER, Vilém. A história do Diabo. São Paulo: Martins, 1965.

Die Schrift (A Escrita) 4a ed. Göttingen: Immatrix, 1992.

. Ficções Filosóficas. Editora da Universidade de São Paulo. 1998.

. Natural:mente: Vários acessos ao significado de natureza - Ensaios brasileiros, filosofia da natureza. São Paulo. Ed. D. cidades, 1979.

. Pós-história: vinte instantâneos e um modo de usar. Duas cidades, São Paulo, 1983.

FOUCALT, M. Microfísica do Poder. Rio de Janeiro, Graal, 1979.

GREIMAS, A. J., COURTÉS, J. Dicionário de Semiótica. Cultrix, São Paulo, 1979.

HUIZINGA, J. Homo Ludens. São Paulo, Perspectiva, 1996.

HILLMAN, James. Cidade \& Alma. São Paulo, Nobel, 1993.

Org. Encarando os deuses. São Paulo, Cultrix /Pensamento, 1993.

O código do ser. Rio de Janeiro, Objetiva, 1997. 
Paranóia. Petrópolis: RJ. Vozes, 1993.

IASBECK, L. C. A. A arte dos Slogans: as técnicas de construção das frases de efeitos do texto publicitários São Paulo: Annambule: Brasília, Upis, 2002.

JUNG, C. G. Aion, estudos sobre o símbolo do si-mesmo. Petrópolis, Vozes, 1976.

KAMPER, D. O trabalho como a vida, São Paulo, Annablume, 1997.

Jan Fabre ou lärte de Lïmpossible. Strassbourg: La Chaufferrie, 1999.

, Wulf, Ch. Looking back on the end of the world .N.Y, Columbia Universit, 1989.

LANDOWSKI, E., OLIVEIRA, A.C., Do inteligível ao sensível. São Paulo, Educ, 1995.

LÉVY, Pierre. A Máquina Universo. Criação, Cognição e Cultura. Porto Alegre, Artmed, 1998.

LUNDBERG, C. Musings on Self, Culture, Inquiry. In: Reframing Org Culture. Califórnia: Sage. 1991.

MACHADO, Arlindo. A televisão levada a sério. São Paulo, editora SENAC, 2000.

McLUHAN, Marshall. Os Meios de Comunicação Extensões do Homem. São Paulo, Cultrix, 1979.

MARCONDES, Filho, Ciro. produção social da loucura, São Paulo, ed. Paulus. 2003.

MORIN, E. O Paradigma Perdido. Portugal: Europa América, 2000.

O Método/O conhecimento do conhecimento. Porto Alegre, Sulina, 1999.

OLIVEIRA, A C. Caderno de Discussão. Centro de Pesquisa Sociosemioticas. São Paulo Ed. CPS, 2002.

PRIGOGINE, Ilya. O Fim das Certezas. São Paulo, Edunesp, 1996.

PROSS, H. Sociedade do Protesto. São Paulo: Annablumme. 1997

PROSS, H., Romano, V. Atrapados em la rede de los medios. Hondarribia: argitaletxe Hiru. 1999.

ROMANO, V. Tiempo y espacio en la comunicación. Hondarribia: Argitaletxe Hiru. 1999.

SERRES, Michel. Os Cinco Sentidos: filosofia dos corpos misturados. Rio de Janeiro, Bertrand Brasil. 2001.

SODRÉ, Muniz. Antropológica do espelho: Uma teoria da comunicação linear em rede. Petropoles, RJ., Vozes, 2002.

WATZLAWICK, P. A realidade inventada. Como sabemos o que cremos saber. Campinas: Ed Psy., 1994.

WATZlAWICK, P; BEAVIN, J. JACKOBSON, D. Pragmática da comunicação Humana. São Paulo, Cultrix, 1993.

WINKIN, Yves. A Nova comunicação. Da teoria ao trabalho de Campo. Campinas, Papiros. 1998. (Org. Etienne Samain). 